\title{
SOBRE ALGUNAS IDEAS LÓGICAS DE JUAN BERNOULLI
}

\author{
MaURicio Beuchot
}

Universidad Nacional autónoma de México

En su opúsculo Positiones logicae de propositionibus, ${ }^{1}$ el matemático Juan Bernoulli (1667-1748) expresa algunas tesis sobre la lógica muy dignas de tenerse en cuenta. Bernoulli pertenece a un periodo de la historia de la lógica que todavía requiere ser explorado con mayor profundidad. Es uno de los pensadores que marcan la transición de la lógica tradicional a la lógica matemática. Los párrafos de las Positiones pueden aportarnos bastante luz sobre la concepción que se tenía de la lógica en esa época. Ciertamente, algunos de esos párrafos sólo repiten conocimientos corrientes en los ámbitos de la escolástica posmedieval y de la lógica renacentista más moderna; pero hay otros que encierran reflexiones y aun innovaciones notables.

Los cinco primeros párrafos de las Positiones no hacen más que repetir la teoría tradicional de la predicación o proposición. Sin embargo, los cuatro siguientes, del VI al IX, presentan una teoría novedosa sobre la proposición cuantificada universalmente. En efecto, Bernoulli la divide en universal esencial y universal accidental. La esencial es la que predica del sujeto algo que ya está contenido en su definición, a saber, el género, o la especie, o ambos. La accidental es aquella en la que la idea del predicado no está contenida en la idea del sujeto; le predica, pues, algo que no está contenido en su esencia, que no es un constitutivo esencial del sujeto, sino una propiedad o un accidente. $\mathrm{Y}$ Bernoulli llega a decir que, en realidad, las universales esenciales son puramente verbales, pues constan de meras palabras: sólo hablan de la misma cosa con diferentes términos y no conducen a nuevos conocimientos.

Si se quiere, esto no es una innovación extraída a partir de la nada. Ya Tomás de Vío, el célebre Cayetano, distinguía la predicación en natural o esencial y artificial o accidental. Aunque — decía- de hecho toda proposición es artificial, por ser la lógica un instrumento o artificio, se pueden dividir, relativamente, las proposiciones en esenciales y acciden-

.1 Contenido en Johann Bernoulli, Opera Omnia. Lausanne-Genève: M. M. Bousquet, 1742, vol. I. 
tales. Las accidentales son las que proporcionan un nuevo conocimiento. Las naturales o esenciales son tautológicas, porque dicen lo mismo de lo mismo; y, según Boecio, ${ }^{2}$ son las más ciertas. Pero Cayetano hablaba de la predicación del individuo sobre sí mismo, como en "Sócrates es Sócrates", ${ }^{3}$ mientras que Bernoulli lo amplía al ámbito de la predicación no individual, sino universal. $\mathrm{Y}$ es algo sumamente impactante el que las reduzca a meras proposiciones verbales, manifestando una concepción de la tautologia emparentable con la del Positivismo lógico y de Wittgenstein en el Tractatus. ${ }^{4}$ Tal interpretación de los principios o axiomas dista mucho de la aristotélico-escolástica. Más bien, los escolásticos consideraban esas proposiciones universales esenciales como las más cognoscitivas, ubicándolas entre los modi dicendi per se ( $\left.\alpha_{\alpha} \theta^{\prime} \alpha u \tau \delta\right),{ }^{5}$ o proposiciones de la manera más propia y científica. Bernoulli, en cambio, las considera como teniendo un sentido meramente verbal.

Algunos párrafos (nn. X-XIII) son dedicados por Bernoulli a la teoría tradicional de la conversión de las proposiciones. Se estipulaban tres tipos de conversión: simple (cambiando el sujeto en predicado y el predicado en sujeto), accidental (cambiando además la cantidad) y por contraposición (introduciendo términos negativos o infinitados). Bernoulli considera que la universal afirmativa no puede convertirse de modo simple, lo cual obedece a la noción que maneja de la cuantificación universal; según él, aunque una proposición áfirmativa sea universal, su predicado "no se toma universalmente, sino sólo según una parte de su extensión, en la cual conviene al sujeto" (n. X). Con ello recoge una idea bien conocida por los escolásticos, quienes decían que la universal afirmativa era universal por virtud del sujeto, no del predicado. ${ }^{6} \mathrm{Y}$, además, que la universal afirmativa no es susceptible de conversión simple, sino accidental. ${ }^{7}$ Igualmente, lo que dice Bernoulli acerca de que el predicado de la particular negativa es universal - por lo cual tampoco puede convertirse de manera simple-, corrobora una doctrina que ya era enseñada, por ejemplo, por Pedro Hispano. ${ }^{8}$

Bernoulli añade (n. XIV) una oposición intermedia entre la contrariedad y la contradicción, por estar compuesta de ambas. Es la que re-

2 A. M. S. Boecio, In Porphyrium Commentaria, lib. II, PL 64, 92 y lib. III, PL 64 , 114.

3 T. de Vio, Caietanus, Commentaria in Porphyrii Isagogen ad Praedicamenta Aristotelis, Ed. I. Marega, Roma: I. Angelicum, 1934, pp. 63-64.

4 L. Wittgenstein, Tractatus logico-philosophicus. Frankfurt a/M.: Suhrkamp Verlag, 1969, 4.461 ss.

5 Aristóteles, Analytica Posteriora, I, 4.

6 D. de Soto, Summulae, Salmanticae: D. a Portonariis, 1575, f. 22ra-b.

7 Ibid., f. 50vb.

8 P. Hispano, Tractatus sive Summulae Logicales. Ed. L. M. de Rijk, Assen: Van Gorcum, 1972, p. 8. 
sulta de dos proposiciones singulares, por ejemplo "Guillermo es rey" y "Guillermo no es rey". Ambas son contrarias, pues difieren sólo en cualidad y coinciden en cantidad; pero también son contradictorias, dado que una será verdadera y la otra falsa, lo cual compete sólo a la contradicción. Tal doctrina parece ser una explicación de observaciones ya hechas por los escolásticos; por ejemplo, Domingo de Soto dice que pueden ser contradictorias dos singulares y que también pueden ser contrarias sin exigencia de universalidad; ${ }^{9}$ pero no se postulaban éstas como constituyendo una oposición especial distinta de la contradictoria y la contraria, formada por contener características de ambas.

Más adelante (nn. XV.XVI) aparecen ciertas consideraciones sobre el valor de verdad de las contrarias y las subcontrarias: "Si dos proposiciones contrarias son ambas falsas, necesariamente las dos subcontrarias serán verdaderas", y a la inversa. Esta tesis pertenecía ya al acervo de la lógica escolástica, pues --se decía_ las proposiciones universales construyen falsedad, dado que exigen mucho para ser verdaderas, mientras que sus particulares (subcontrarias entre sí) construyen verdad, dado que exigen muy poco (que se cumplan en un solo caso) para ser verdaderas. ${ }^{10}$ También lo que dice acerca de que si una de las contrarias es verdadera, necesariamente una de las subcontrarias será verdadera y la otra falsa, es ratificación de una regla ya conocida.

El párrafo XVII revitaliza la conversión por contraposición, ciertamente conocida y utilizada por los escolásticos, ${ }^{11}$ pero muy poco y con muchas reservas, ${ }^{12}$ llegando algunos a negar su validez. ${ }^{13} \mathrm{Si}$ se admite esa conversión de proposiciones, se pueden simplificar los silogismos. ${ }^{14}$ Esto lo aprovecha y explota Bernoulli para reducir los silogismos. Así, reduce los cuatro modos directos de la primera figura a sólo dos; los cuatro de la segunda figura a otros dos, y los seis de la tercera figura a tres. Todo ello en base al manejo de los términos negativos o infinitados (nn. XVIII$\mathrm{XXI}$ ). Cosa que no fue cabalmente desarrollada por los escolásticos, y aparece con la modernidad, como se puede ver, por ejemplo, en la obra de Leibniz. ${ }^{15}$

Un segmento del opúsculo de Bernoulli está dedicado a reflexiones

9 D. de Soto, op. cit., f. 41 ra.

10 T. de Mercado, Commentaria in textum Petri Hispani. Hispali: F. Diaz, 1571, f. $43 \mathrm{rb}$.

11 P. Hispano, op. cit., p. 8.

12 D. de Soto, op. cit., f. 5lra; J. de Sto. Tomás, Ars Logica, ed. B. Reiser, Torino: Marietti, 1930, p. $47 \mathrm{a}-\mathrm{b}$.

13 T. de Mercado, op. cit., f. 54ra.

14 D. P. Henry, "Negative Terms and Buridan's Syllogistic", en J. Pinborg (ed.),

The Logic of John Buridan, Copenhagen: Museum Tusculanum, 1976, pp. 115-120.

15 G. W. Leibniz, De arte combinatoria. Ed. Gerhardt, Hildesheim: G. Olms, vol. IV, pp. 46-56. 
semántico-pragmáticas de cierto interés. Además de las oraciones asertivas, tanto simples como compuestas, Bernoulli señala las que él llama "vagas", a causa de que no se les puede asignar un valor de verdad. Tales son, por ejemplo, las interrogativas y las imperativas. Aclara que, "hablando con propiedad, tales expresiones no son proposiciones, pues la intención del hablante no es afirmar ni negar algo, y, por eso, consideradas en sí mismas, no son verdaderas ni falsas" (n. XXIII). Sin embargo, de una manera cercana a la de Austin, ${ }^{16}$ les da una interpretación que podríamos llamar "performativa", por oposición a la "constatativa" —en la que se da verdad o falsedad-, pues no pueden ser verdaderas ni falsas, pero pueden ser afortunadas o desafortunadas en cuanto al cumplimiento de la intención del hablante. En sus propias palabras: "Así, pues, la operación de la mente que estas expresiones producen en aquel a quien se profieren es como algo intermedio entre la simple aprehensión y el juicio. Pues suscitan algo más que una simple aprehensión; porque la mente no se aquieta en la mera contemplación de las ideas, sino que además se determina a responder o a hacer aquello que se desea. Pero suscitan menos que el juicio, a saber, porque la mente no forma ni la conveniencia ni la discrepancia de las ideas, esto es, ni afirmación ni negación" (n. XXIV).

Trata además de una clase de proposiciones que él denomina "indiferentes", donde en realidad se está expresando con suficiente evidencia el carácter relacional de la proposición (nn. XXV-XXVI). Es algo que ya estaba precontenido en la escolástica, ${ }^{17}$ y que Peter Geach subraya como un elemento que será muy importante para la lógica de Frege -habiendo pasado desapercibido para otros lógicos de los siglos xvir y xix-. Según la expresión de Bernoulli, en "A algún hombre le acontece ir a Corinto" el sujeto puede ser "algún hombre", porque de él se predica correctamente "le acontece ir a Corinto"; pero también, bajo otro respecto, el sujeto puede ser "ir a Corinto", porque de él se predica con igual corrección "a algún hombre le acontece". Pues bien, esto corresponde a lo que Geach encuentra como algo que Frege recupera, a saber, la insistencia en que una proposición como "Pedro golpeó a Malco" es tanto una predicación sobre Pedro como una predicación distinta sobre Malco. Aunque en perspectiva diferente, tanto "Pedro" como "Malco" pueden ser sujetos lógicos de esa proposición, se insertan en el mismo contenido lógico. ${ }^{18}$

${ }^{16}$ J. L. Austin, How to Do Things with Words. Cambridge, Mass.: Harvard University Press, 1967, pp. 4-6 y 14.

17 M. Beuchot, La filosofía del lenguaje en la Edad Media. México: Instituto de Investigaciones Filosóficas, UNAM, 1981, pp. 90-91.

18 P. T. Geach, Reference and Generality. Ithaca and London: Cornell University Press, 1970 (Emended Edition. 2d print), pp. 28-29. 
Finalmente, el trabajo de Bernoulli exhibe una marcada atención hacia las difíciles proposiciones que los escolásticos llamaban "exponibles", i.e. las que se han de parafrasear en otras proposiciones derivadas de ellas (por inferencia) para captar plenamente su sentido. Trata primero de las proposiciones iniciativas y cesativas, a saber, las que llevan las partículas "incipit" comienza) o "desinit" (cesa); y con sobrada razón las examina, pues fueron precisamente estas dos clases de proposición las que, desde el ángulo de la lógica, influyeron en los desarrollos de la física efectuados por los escolásticos de línea nominalista próximos a Galileo. ${ }^{19}$ Pero añade otras que no habían sido suficientemente consideradas o ni siquiera mencionadas por ellos (nn. XXVII-XXX), como las continuativas, las intermisivas, las adventivas y las preteritivas. Sobre ellas aclara que son compuestas en el sentido; pues, afirmando o negando una cosa, al mismo tiempo afirman o niegan tácitamente otra. $Y$ termina diciendo: "De este modo, hay muchas proposiciones que, aun cuando son consideradas como simples, se puede mostrar que son exponibles" (n. XXXI).

Haciendo un balance de las ideas contenidas en este opúsculo de Juan Bernoulli, podemos decir que manejaba con soltura los conocimientos lógicos disponibles en su tiempo; pero, lo que es más importante, se atrevió a dar un uso sumamente amplio a esos instrumentos que requería para sus construcciones matemáticas. Lo demuestra, por ejemplo, su noción de la predicación "esencial" o tautológica, que libremente emplea como "verbal"; asimismo, su reducción de los modos del silogismo; y, por último, su agudeza al tratar de las complicadas proposiciones exponibles, muy dispuestas para ser aplicadas a la física con la nueva perspectiva matemática. Estos son algunos puntos notables, entre otros muchos, de la lógica tal como era utilizada por Bernoulli.

19 N. Kretzmann, "Incipit/Desinit", en P. K. Machamer - R. G. Turnbull (eds.), Motion and Time, Space and Matter. Interrelations in the History of Philosophy and Science. Columbus: Ohio University Press, 1976, pp. 101-136. 